\title{
Scientific progress versus ecological influence on Schistosoma mansoni transmission
}

\author{
Amélia Ribeiro de Jesus ${ }^{[1],[2]}$ and José Antônio Pacheco de Almeida ${ }^{[3]}$
}

[1]. Departamento de Medicina, Laboratório de Biologia Molecular, Universidade Federal de Sergipe, Aracaju, SE. [2]. Institutos Nacionais de Ciência e Tecnologia, Instituto de Investigação em Imunologia, Conselho Nacional de Desenvolvimento Científico e Tecnológico, São Paulo, SP. [3]. Departamento de Geografia, Universidade Federal de Sergipe, Acaraju, SE.

In this issue of the Revista da Sociedade Brasileira de Medicina Tropical / Journal of the Brazilian Society of Tropical Medicine, we are delighted by the broad review and personal experience of Professor José Roberto Lambertucci regarding hepatosplenic schistosomiasis ${ }^{1}$. He is one of the leading clinical experts in schistosomiasis and among those responsible for the high quality of research that has helped explain several clinical aspects of the disease.

In this editorial, I remember the great scientists who were true heroes and who braved winding roads to study schistosomiasis in Brazil, and I also discuss the socioeconomic and ecological aspects that interfere with efforts to control schistosomiasis transmission.

Schistosomiasis is a disease that has accompanied humankind since we began to preferentially inhabit plains, and it has not been quelled by modern progress. In fact, it is among the few parasitic diseases whose worldwide distribution continues to increase. Human efforts have been far more successful than technology-based ones in the struggle to understand and control schistosomiasis. In addition to Professor Lambertucci, several other Brazilian and international scientists have contributed toward our understanding of schistosomiasis. Even in the past, lacking technology and using only their clinical skills, these scientists classified the disease, implemented measures to control its transmission (even managing to eliminate the disease in certain areas), developed simple diagnostic tools that are still being used, tested several drugs while establishing an effective oral treatment for the disease and described a decrease in portal hypertension after a particular $S$. mansoni treatment. In fact, the mass application of this treatment for schistosomiasis sharply reduced the prevalence of severe disease in Brazil. More recently, following new developments in laboratory research methods, several new aspects of the immune response to infection and granuloma formation have been reported.

\footnotetext{
Address to: Dr ${ }^{\text {a }}$ Amélia Ribeiro de Jesus. Lab Biologia Molecular/Hospital Universitário/UFS. Rua Claudio Batista s/n, Campus de Ciências Biológicas e da Saúde, Sanatório, 49060-100 Aracaju, SE, Brasil.

Phone: 5579 2105-1806

e-mail: jesus-amelia@uol.com.br

Receveid 2 April 2014

Accepted 15 April 2014
}

However, the environmental changes necessary to combat schistosomiasis transmission have progressed at a slower pace. While modifying the environment to suit our needs, humankind has provided new habitats for snails from the genus Biomphalaria, for example, through the construction of dams and irrigation systems using primitive methods. Even the urbanization process creates environments that lack infrastructure or sanitation and are fed by migratory processes of men and snails, leading to an escalation of the disease in an entirely new space ${ }^{2,3}$.

Environmental factors significantly influence the onset of schistosomiasis because the completed life cycle of the parasite requires eggs to be released from feces into the environment. In Brazil, especially in poor rural areas, it is still common to encounter conditions that favor infection with S. mansoni, as well as co-infections of S. mansoni and intestinal nematodes, such as Ascaris lumbricoides, Trichuris trichiura and hookworm.

The Brazilian program for schistosomiasis control helped to reduce the prevalence of the disease, but because of focal nature of this disease, schistosomiasis infection rates have remained stable in several regions. One example of this phenomenon is in the State of Sergipe. Our group reviewed data from Sergipe's Schistosomiasis Control Program from 2005 to 2008 and analyzed the frequency and geographic distribution of infections by $S$. mansoni and other intestinal parasites ${ }^{4}$ These data were exported to the software Spring 5.0.5 to prepare thematic maps of spatial and temporal distribution by year of evaluation. The prevalence in Sergipe remained stable, ranging from $13.61 \%$ $(14,471 / 106,287)$ in 2005 to $10.56 \%(8,329 / 78,859)$ in 2008 . Additionally, analysis of the maps revealed a high prevalence of disease in certain municipalities of Sergipe, ranging from $30 \%$ to $45 \%$. Furthermore, we found that cities whose prevalence of schistosomiasis was higher than $15 \%$ had a lower hygiene index, which is an indicator that measure the percentage of the sewage system in municipalities under the jurisdiction of the Brazilian Department of Water Resources (Superintendência de Recursos Hidricos $-\mathrm{SRH})^{5}(\mathrm{p}=0.05)$. We highlight the importance of improving the control of environmental risk factors and education as a means to reduce the prevalence of schistosomiasis.

The recent introduction of the geographic information system (GIS) to epidemiological studies helps to not only 
map cases but also predict high-risk areas. The GIS provides improved techniques for the storage, query and spatial analysis of data developed from a set of tools for handling spatial information. It is designed to identify variables that reveal the social, economic and environmental factors associated with health risks ${ }^{4}$. GIS information adds a new perspective on the epidemiology and ecology of parasitic diseases on a geographical scale. The application of GIS enhances traditional approaches and allows the surveillance of the distribution of parasitic diseases to direct the efforts of control programs, as it helps to inform which interventions should be targeted and where they should be administered geographically, thus reducing costs and improving efficiency ${ }^{6}$.

Recently, our group conducted a cross-sectional study that applied geospatial analysis to study the epidemiology of Schistosoma mansoni, intestinal parasites and co-infections in Ilha das Flores, Sergipe, Brazil. We collected individually georeferenced clinical, socioeconomic, educational, epidemiological and parasitological data from 500 subjects and analyzed the data using conventional statistics and risk maps produced from kernel estimation. We found that the prevalence rate for $S$. mansoni was $24 \%$. We observed associations between $S$. mansoni infection and male gender $(65.2 \%$ males, $\mathrm{p}=0.003)$, the occupation of farmer $(p<0.001)$ or fisherman $(p<0.001)$, low educational level $(p<0.001)$, low income $(p=0.0005)$, contact with water $(\mathrm{p}<0.001)$ and drinking untreated water $(\mathrm{p}<0.001)$. The kernel estimator maps indicated that the higher risk areas coincided with the poorest regions of the villages and with the parts of the villages with inadequate sewage systems (personal communication, in process for publication). Although these data confirm several past observations, the estimator maps were generated from a scientifically proven process that quantifies these associations and maps the sites where interventions should be prioritized within the municipality.

We also investigated the spatial distribution of the intermediate snail host Biomphalaria within the same endemic area as that of schistosomiasis, evaluating the relationship between irrigation and types of natural water sources on the one hand and the influences of location and time of water exposure on the intensity of human infection on the other hand ${ }^{7}$. GIS was used to map the distribution of the intermediate snail hosts in Ilha das Flores, Sergipe, Brazil, in combination with water contact levels and parasitological examinations conducted by the epidemiological survey. We observed a direct correlation between the intensity of human infection with $S$. mansoni and contact with irrigation projects, but the correlation did not persist when we considered human contact with natural water sources. Malacological studies that were conducted to identify the snail species and infection rates indicated that B. glabrata is the main species responsible for human schistosomiasis in the municipality but that $B$. straminea is also involved. In addition, the results provide evidence for competitive selection between the two species: at each of the collection points, only one species was found, with a predominance of B. glabrata in the irrigation systems and rice fields and a predominance of $B$. straminea in the natural water sources and rice fields ${ }^{7}$. There is currently a predominance of $B$. glabrata over $B$. straminea within the study area. However, Melo and Barbosa, in 1968, and Figueiredo, in 1988, collected snail samples in this region of the backwoods of the São Francisco River valley and showed that $B$. straminea was the exclusive species found at that time ${ }^{8,9}$ In 1967, an irrigation system was created in this municipality. Our data showing the predominance of $B$. straminea in natural water sources indicate that this species is the natural snail found inhabiting this type of area and that $B$. glabrata has replaced $B$. straminea. Because $B$. glabrata is less resistant to dry weather conditions than $B$. straminea, the irrigation system, which enriches the soil with food and water, also promotes the survival of this species. It has been shown that $B$. straminea replaces $B$. glabrata both in the natural environment and under laboratory conditions ${ }^{10}$. However, in this area, we demonstrate that under the specific environmental conditions caused by the irrigation system, $B$. glabrata is successfully surviving and is the major species responsible for human $S$. mansoni infection ${ }^{7}$. This knowledge is important for understanding the process of natural selection responsible for the establishment of schistosomiasis in new areas and could potentially lead to future control schemes based on natural, biological control.

In his review, Prof. Lambertucci ${ }^{1}$ also called attention to the coinfections and diseases associated with $S$. mansoni infection. In the same study in Ilha das Flores, State of Sergipe, associations among Trichuris trichiura (54.8\%), Ascaris lumbricoides (49.2\%), hookworm (17.6\%) and Entamoeba histolytica/dispar (7\%) were observed. Only 59/500 (11.8\%) individuals were not infected, whereas 279/500 (55.8\%) had three or more parasites. These intestinal parasitic infections were also associated with socioeconomic and educational factors. For example, we found associations of $A$. lumbricoides and hookworm infections with low income ( $\mathrm{p}=0.002$ and $\mathrm{p}=0.01$, respectively) and associations of $A$. lumbricoides and T. trichiura infections with drinking untreated water $(\mathrm{p}=0.02$ for both) and with open-air sewage systems ( $\mathrm{p}=0.001$ and $\mathrm{p}=0.0005$, respectively) (personal communication, in process for publication).

These findings call for an integrated public health approach to effectively control schistosomiasis and other parasitic infections. It is time for Brazilian development to engender a faster social impact. As science progresses, we must make rapid progress in the control of the neglected diseases that affect our country.

\section{CONFLICT OF INTEREST}

The authors declare that there is no conflict of interest.

\section{REFERENCES}

1. Lambertucci JR. Revisiting the concept of hepatosplenic schistosomiasis and its challenges using traditional and new tools. Rev Soc Bras Med Trop 2014; 47:130-136.

2. Coutinho AD, Silva ML, Gonçalves JF. Estudo Epidemiológico da Esquistossomose Mansônica em áreas de irrigação do nordeste brasileiro. Cad Saude Publica 1992; 8:302-310. 
3. Guimarães ICS, Tavares-Neto J. Transmissão urbana de esquistossomose em crianças de um bairro de Salvador, Bahia. Rev Soc Bras Med Trop 2006; 39:451-455.

4. Rollemberg CVV, Santos CMB, Silva MMBL, Souza AMB, Silva AM, Almeida JAP, et al. Epidemiological characteristics and geographical distribution of schistosomiasis and geohelminths, in the State of Sergipe, according to data from the Schistosomiasis Control Program in Sergipe. Rev Soc Bras Med Trop 2011; 44:91-96.

5. Superintendência de Recursos Hídricos [Internet]. Superintendência de Recursos Hídricos. 2010 - [Cited April 11]. Available at: http://www. seplantecsrh.se.gov.br/.

6. Hino PV, Sassaki CM, Nogueira JA, Santos CB. Geoprocessing in health area. Rev Latino-am Enfermagem 2006; 14:939-943.
7. Barboza DM, Zhang C, Santos NC, Silva MMBL, Rollemberg CVV, Amorim FJR, et al. Biomphalaria species distribution and its effect on human Schistosoma mansoni infection in an irrigated area used for rice cultivation in northeast Brazil. Geospatial Health 2012; 6:S103-S109.

8. Mello DA, Barbosa FS. Estudos sobre os planorbídeos transmissores da esquistossomose mansônica no estado de Sergipe. Gaz Med Trop 1969; 21:246-253

9. Figueiredo CCSB. Dispersão de Biomphalaria straminea no estado de Sergipe: um estudo comparativo com dezenove anos de intervalo. Mem Inst Oswaldo Cruz 1989; 84:383-387.

10. Barbosa FS. Possible competitive displacement and evidence of hybridization between two Brazilian species of planorbid snails. Malacologia 1973; 14:401-408. 